\title{
AMPA Receptor Stimulation within the Central Nucleus of the Amygdala Elicits a Differential Activation of Central Dopaminergic Systems
}

\author{
Thomas A Stalnaker' and Craig W Berridge*,1,2 \\ 'Psychology Department, University of Wisconsin-Madison, Madison, WI, USA; ${ }^{2}$ Psychiatry Department, University of Wisconsin-Madison, \\ Madison, WI, USA
}

\begin{abstract}
Appetitive and aversive arousing stimuli increase rates of dopamine (DA) release, particularly within the prefrontal cortex (PFC). Evidence suggests an activating influence of both the central ( $\mathrm{CeA}$ ) and basolateral (BIA) nuclei of the amygdala on DA neurotransmission. For example, lesions of CeA block stressor-induced increases in DA release. Additionally, electrical stimulation of BIA increases DA release in select terminal fields. Previous studies indicate that glutamatergic AMPA receptors modulate CeA and BIA output. However, the extent to which AMPA receptors participate in amygdala-dependent activation of DA neurotransmission is unknown. The current studies examined the effects of bilateral AMPA infusions within CeA or BIA on post-mortem and in vivo microdialysis indices of DA release. Additionally, stress is associated with moderate increases in serotonin (5-HT) neurotransmission that are also blocked by $\mathrm{CeA}$ lesions. Thus, the current studies also examined the impact of AMPA infusions on post-mortem indices of 5-HT utilization. AMPA infusion into CeA, but not BIA, increased post-mortem indices of DA and 5-HT release in a pattern comparable to that observed under appetitive/aversive conditions. In vivo microdialysis studies confirmed that AMPA infusions into CeA, but not BIA, increase extracellular PFC DA levels. When infused into sleeping animals, CeA-AMPA infusion also elicited a rapid-onset transition into waking. Thus, CeA-AMPA receptors exert an excitatory influence on DA and 5-HT neurotransmission and on behavioral state. Combined, these results suggest that CeA-AMPA receptors may participate in the coordination of neural systems involved in the regulation of behavioral state under high-arousal conditions.

Neuropsychopharmacology (2003) 28, 1923-1934, advance online publication, 13 August 2003; doi: I0.1038/sj.npp. 1300268
\end{abstract}

Keywords: dopamine; prefrontal cortex; basolateral nucleus of the amygdala; arousal; serotonin; waking

\section{INTRODUCTION}

Central dopaminergic systems have been implicated in a broad array of state-dependent affective and cognitive processes. Dopaminergic neurons project widely throughout the brain and are responsive to salient and arousing sensory stimuli (both appetitive and aversive; Thierry et al, 1976; Dunn and Everitt, 1988; Roth et al, 1988; Fiorino et al, 1997; Bassareo and Di Chiara, 1997; Ahn and Phillips, 1999). A differential sensitivity of dopaminergic efferents to these stimuli is observed across terminal fields: dopamine (DA) efferents projecting to the prefrontal cortex (PFC) display the greatest degree of activation, with lesser magnitude increases in DA release observed within the nucleus

\footnotetext{
* Correspondence: Dr CW Berridge, Psychology Department, 1202 W. Johnson St., Madison, WI 53706-I6II, USA. Tel: + I 608265 5938, Fax: + I 608262 4029, E-mail: berridge@wisc.edu

Received 25 February 2003; revised 06 June 2003; accepted 09 June 2003

Online publication: 13 June 2003 at http://www.acnp.org/citations/ Npp06 / 303030080/default.pdf
}

accumbens (NAcc), and lesser still within the striatum (Dunn and Everitt, 1988; Abercrombie et al, 1989; Bassareo and Di Chiara, 1997; Berridge et al, 1999; Cousins et al, 1999).

Both the central (CeA) and basolateral (BlA) nuclei of the amygdala, two structures implicated in aversively and appetitively motivated learning and behavior (Pascoe and Kapp, 1985; Gallagher and Chiba, 1996; Parkinson et al, 2000; LeDoux, 2000; Davis, 2000; Cardinal et al, 2002), appear to influence rates of DA neurotransmission. For example, lesions of CeA block stressor-induced increases in DA release in PFC and NAcc (Davis et al, 1994; Goldstein et al, 1996). Recent observations using lidocaine infusions into CeA suggest that $\mathrm{CeA}$ also contributes to increases in DA neurotransmission associated with appetitive conditions (Ahn and Phillips, 2003). Although the circuitry underlying CeA-dependent alterations in DA neurotransmission remains unknown, anatomical evidence indicates that CeA provides direct (Gonzales and Chesselet, 1990; Wallace $e t$ al, 1992) or indirect (Fadel et al, 2001; Fadel and Deutch, 2002) input to brainstem dopaminergic nuclei. Additional 
evidence also suggests a prominent role of $\mathrm{BlA}$ in the modulation of DA neurotransmission. For example, electrical stimulation of BlA increases DA efflux within NAcc (Floresco et al, 1998; Howland et al, 2002) and PFC (Jackson and Moghaddam, 2001).

The above-described observations suggest a pivotal role of both $\mathrm{CeA}$ and $\mathrm{BlA}$ in the modulation of DA neurotransmission, at least under certain environmental conditions. The effects of CeA lesions and lidocaine infusions into CeA demonstrate the necessity of this nucleus in the enhancement of DA neurotransmission observed under certain high-arousal environmental conditions. However, the extent to which CeA neuronal activation is sufficient to elicit a stress- and/or reward-like activation of cerebral dopaminergic systems remains unclear.

Currently, little is known regarding the neurochemical identity of afferents to $\mathrm{CeA}$ or BlA involved in the modulation of DA neurotransmission. However, available evidence indicates a prominent role of glutamatergic receptors within $\mathrm{CeA}$ and $\mathrm{BlA}$ in the acquisition and expression of conditioned aversive responses (Kim et al, 1993; Walker and Davis, 2002, 1997). This suggests the possibility that glutamatergic receptors participate in CeAand/or BlA-dependent alterations in rates of DA neurotransmission.

To better address these issues, the current studies examined the effects of microinfusion of the glutamatergic agonist AMPA into $\mathrm{CeA}, \mathrm{BlA}$, or surrounding regions, on post-mortem and microdialysis indices of DA release within select terminal fields in unanesthetized rats. Additionally, $\mathrm{CeA}$ appears to exert a modulatory influence on serotonin (5-HT) utilization in stress. For example, lesions of CeA prevent stressor-induced increases in 5-HT utilization (Goldstein et al, 1996). Thus, to assess the extent to which AMPA-induced alterations in rates of DA neurotransmission are specific to DA or are also associated with enhanced rates of 5-HT neurotransmission, the current studies also examined the effects of CeA- and BlA-AMPA infusions on indices of 5 -HT utilization.

\section{MATERIALS AND METHODS}

\section{Animals and Surgery}

Male Sprague-Dawley rats (280-350 g; Charles River, Wilmington, MA, USA) were housed in pairs on a 13-11 h cycle (lights on 0600) and provided ad libitum access to food and water. Stereotaxic surgery was performed using halothane anesthesia administered through a nose cone, with the skull level and body temperature maintained at approximately $36^{\circ} \mathrm{C}$. In all cases, guide cannulae (26 or 23 ga.; Plastics One, Roanoke, VA, USA) were implanted bilaterally aimed at either CeA $(-2.3 \mathrm{~A}, \pm 4.0 \mathrm{~L},-7.15 \mathrm{~V})$ or $\mathrm{BlA}(-2.85 \mathrm{~A}, \pm 4.8 \mathrm{~L},-7.6 \mathrm{~V})$, or immediately dorsal to $\mathrm{CeA}(-2.3 \mathrm{~A}, \pm 4.0 \mathrm{~L},-6.7 \mathrm{~V})$. For in vivo microdialysis studies, a microdialysis probe was implanted within the left $(n=11)$ or right $(n=3) \operatorname{PFC}\left(+3.2 \mathrm{~A}, \pm 1.0 \mathrm{~L},-5.0 \mathrm{~V}\right.$ at $\left.4^{\circ}\right)$. In some cases, a bipolar surface-to-depth EEG electrode was implanted within the contralateral PFC $(+3.0 \mathrm{~A}, \pm 1.5 \mathrm{~L}$, $-1.5 \mathrm{~V}$ ), as described previously (Berridge and Foote, 1991, 1996; Berridge and Abercrombie, 1999). Cannulae, microdialysis probes, and EEG electrodes were held in position with acrylic cement (Plastics One). A stainless-steel wire stylet was inserted and attached to each cannula via a threaded connector (Plastics One). For post-mortem studies, surgery was performed 5-10 days prior to testing. For microdialysis studies, surgery was performed on the day prior to testing (see below). All efforts were made to minimize animal suffering and to minimize the number of animals used. All experiments were conducted in accordance with University of Wisconsin-Madison Institutional Animal Care and Use Committee guidelines, and the National Institutes of Health Guide for the Care and Use of Laboratory Animals.

\section{Drug Infusions}

Infusions were made using the following procedures. PE20 tubing, filled with water, was connected to the infusion needle and housed within a stainless-steel coil spring. The distal end of the tubing was connected to a $10 \mu$ l syringe, the plunger of which was advanced by a microprocessorcontrolled infusion pump (Harvard Apparatus, South Natick, MA, USA). An air bubble was placed in the tubing to permit visualization of fluid displacement during advancement of the syringe plunger. The needle and tubing were loaded with approximately $5 \mu$ l of vehicle or AMPA hydrobromide (RBI; Natick, MA, USA) dissolved in vehicle $(20 \mathrm{ng} / \mu \mathrm{l})$. Artificial extracellular fluid (AECF) containing $0.5 \%$ Pontamine Sky Blue dye served as vehicle. An approximately $50 \mathrm{nl}$ air bubble was used to separate vehicle or AMPA from water contained within the PE20 tubing. AMPA or vehicle was infused bilaterally using a procedure that consisted of two 1 -min infusions at 150 or $250 \mathrm{nl} / \mathrm{min}$, separated by $2 \mathrm{~min}$. This infusion procedure was based on results obtained in pilot studies that examined the actions of AMPA on locus coeruleus (LC) neuronal discharge rate, using a previously described infusion/recording probe (Berridge and Foote, 1991). In these studies $(n=2), 150 \mathrm{nl}$ of AMPA $(20 \mathrm{ng} / \mu \mathrm{l})$ elicited a robust short-duration increase in neuronal discharge rate when the infusion needle was $\sim 200-400 \mu \mathrm{m}$ from the recording electrode (average increase over baseline was $516 \%$ for $3.5 \mathrm{~min}$, at which point neuronal discharge had returned to baseline levels). Higher AMPA concentrations or larger infusion volumes elicited a brief and robust neuronal activation followed by an abrupt cessation of neuronal discharge activity (ie depolarization block), which partially recovered over 3-4 min. In the range of doses used in these studies (see below), two 1-min infusions separated by $2 \mathrm{~min}$ resulted in sustained increases in neuronal activity for 6-7 $\mathrm{min}$, with a subsequent return to baseline levels of activity.

\section{Experimental Procedures}

Post-mortem studies. Rats were handled daily and weighed approximately every third day from the time of surgery until testing (8-11 days total). To minimize the stress of the infusion procedure, animals were also habituated to the experimental procedure by exposing them to a simulated infusion regimen for 3 consecutive days ending 2 days prior to testing. On the day of testing, each home-cage was moved to an adjacent room (to avoid disturbing the remaining animals in the colony room) and 
bilateral drug or vehicle infusions were made within CeA or BlA. As described above, two 1-min bilateral infusions were made, with a 2 -min period separating the two infusions.

Two experiments were conducted. In Experiment 1a, 33 ga. needles were used, and infusions consisted of either $150 \mathrm{nl}$ of vehicle or $3.0 \mathrm{ng}$ AMPA. In Experiment 1b, 30 ga. needles were used, and infusions consisted of either $250 \mathrm{nl}$ vehicle or $5.0 \mathrm{ng}$ AMPA. A larger infusion volume and larger diameter needles were used in Experiment $1 \mathrm{~b}$ because histological data from Experiment 1a indicated that, in a moderate percentage of cases, infusate either did not enter the tissue or did not diffuse radially from the needle-tip (see Results).

At $30 \mathrm{~min}$ following infusions, animals were removed from their cages, decapitated, and the brains removed and dissected rapidly on ice. Dissection was performed with the combined use of a brain mold (ASI, Warren, MI, USA) to generate coronal slices, and free-hand dissection. The following brain regions were collected, using a protocol described previously (Dunn and File, 1983; Berridge et al, 1999): left and right medial PFC (LPFC and RPFC), collected from a $2 \mathrm{~mm}$ slice starting $2 \mathrm{~mm}$ posterior to the anteriormost aspect of the frontal cortex; cingulate cortex, collected from a $2 \mathrm{~mm}$ slice starting $1 \mathrm{~mm}$ posterior to the PFC slice; NAcc, divided into shell and core subdivisions, taken from the same slice as cingulate cortex; and, striatum, also taken from the same slice as cingulate cortex. Dissected tissue was weighed, frozen on dry ice, and stored at $-80^{\circ} \mathrm{C}$.

In vivo microdialysis studies. For microdialysis studies, probes (see below) were lowered slowly over a 5-10-min period. This procedure was based on previous studies indicating that slow implantation results in substantially higher extracellular levels of norepinephrine and DA. Following probe implant, animals were placed in a Plexiglas testing chamber $(32 \times 32 \times 40 \mathrm{~cm})$ overnight. This chamber was housed in a wooden sound-attenuating outer chamber containing a $15 \mathrm{~W}$ light bulb, a speaker through which white noise $(80 \mathrm{~dB})$ was played, and a $12 \mathrm{~V}$ fan running at reduced speed. A $10-\mathrm{cm}$ hole in the top of the chamber permitted passage of infusion, EEG recording, and microdialysis lines. A second $10-\mathrm{cm}$ hole in the front of the chamber permitted videotaping of the animal. A steel coil spring containing the microdialysis probe inlet and outlet was attached to a liquid swivel (Instech Laboratories Inc., Plymouth Meeting, PA, USA) held in a counter-balance outside the outer chamber. A 3-ml syringe containing AECF was connected to the inlet of the liquid swivel via PE20 tubing, and the outlet of the liquid swivel was connected to the microdialysis probe inlet tubing. The plunger of the syringe was advanced by a microprocessor-controlled infusion pump (Harvard Apparatus, South Natick, MA, USA). Fused silica tubing provided outflow to a sample collection vial outside the soundattenuating chamber (see below).

On the day following surgery, stylets were removed from the guide cannulae and 30 ga. needles were inserted and secured via plastic threaded sleeves. Animals were then left undisturbed while baseline dialysate samples were collected (16-min collection time). Behavior and, when appropriate, EEG were simultaneously recorded onto videotape. EEG was also recorded onto a polygraph. Following a minimum of three to four consecutive samples during which the animal mostly slept and minimal variation in DA levels was observed (ie less than $10 \%$ variation from the mean level), bilateral drug or vehicle infusions were made within CeA or $\mathrm{BlA}$. In several additional cases, unilateral drug infusions were made within CeA. Given that the infusion pump was outside the testing chamber, animals were not handled or otherwise disturbed by the infusion procedure. Infusions were performed as described for Experiment 1b. Following infusions, dialysate samples were collected until DA levels returned to baseline levels for two consecutive samples. Note that 16-min samples were collected continuously and thus the first post-infusion sample period included the 4min infusion procedure. In most cases, a final dialysate sample was collected during which the animal was handled repeatedly over a 60-s period to elicit a state of moderate arousal or stress. This procedure permitted a comparison of AMPA-induced alterations in DA release with those elicited by stress or high arousal.

\section{High-Pressure Liquid Chromatography (HPLC) Analyses}

In both post-mortem and microdialysis studies, the samples were analyzed using HPLC with electrochemical detection. Post-mortem samples were homogenized in $0.1 \mathrm{~N}^{\mathrm{HClO}_{4}}$ containing an internal standard (isoproterenol), centrifuged, and injected onto the HPLC system for analyses of DA, 3,4-dihydroxyphenylacetic acid (DOPAC), 5-HT, and 5hydroxyindole-acetic acid (5-HIAA), as described previously (Berridge et al, 1999). The HPLC system consisted of an ESA 580 pump set at $0.65 \mathrm{ml} / \mathrm{min}$, a C18 column $(150 \times 3.2 \mathrm{~mm}$; ESA, Inc., Chelmsford, MA, USA $)$, and an amperometric detector (Waters Corp., Milford, MA, USA) with the potential set to $+0.65 \mathrm{~V}$. The output of the detector was sent to a computer running analytical software (EZChrom, Scientific Software, Inc., San Ramon, CA, USA). Mobile phase consisted of $0.05 \mathrm{M} \mathrm{NaH}_{2} \mathrm{PO}_{4}, 0.05 \mathrm{M}$ sodium citrate, $100 \mu \mathrm{M}$ EDTA, $9 \% \mathrm{v} / \mathrm{v}$ methanol, and $0.15-$ $0.25 \mathrm{mM}$ octyl sodium sulfate, at $\mathrm{pH}$ 2.8-3.4. All reagents were obtained from Fisher Scientific (Itasca, IL, USA) except for octyl sodium sulfate (Sigma Chemical Co., St Louis, MO, USA). Concentrations of DA, DOPAC, 5-HT, and 5-HIAA in each region were calculated from the combined use of external and internal standards and expressed as pg per mg wet tissue. Ratios of DOPAC/DA and 5-HIAA/5-HT were calculated as an index of DA and 5 -HT release, respectively.

For in vivo microdialysis studies, DA levels were measured using previously described methods (Abercrombie et al, 1989; Berridge and Abercrombie, 1999). Briefly, AECF was delivered at a rate of $1.5 \mu \mathrm{l} / \mathrm{min}$ through PE10 tubing to a length of Spectra/Por hollow dialysis membrane (MW cutoff $6000 \mathrm{Da}$, o.d. $250 \mu \mathrm{m}$ ). The membrane was sealed and attached to the PE10 tubing with epoxy. The length of functional dialysis membrane in contact with tissue was $4 \mathrm{~mm}$. A $75-\mathrm{cm}$ length of fused silica $(150 \mu \mathrm{m}$ o.d., $75 \mu \mathrm{m}$ i.d.) provided outflow. Aliquots of $20 \mu \mathrm{l}$ were injected onto an HPLC system consisting of an ESA 580 pump set at $0.65 \mathrm{ml} / \mathrm{min}$, a Velosep C18 $100 \times 3.2 \mathrm{~mm}$ cartridge column, and an ESA Model 5200A detector with two electrodes in series: $-25 \mathrm{mV},+220 \mathrm{mV}$. The mobile 
phase consisted of $200 \mathrm{mM}$ sodium phosphate, $100 \mu \mathrm{M}$ EDTA, $0.30-0.38 \mathrm{mM}$ octyl sodium sulfate, and $5 \% \mathrm{v} / \mathrm{v}$ methanol, at a $\mathrm{pH}$ of 4.85 . The quantitation limit for DA (using a criterion of three times background noise) was approximately $0.3 \mathrm{pg}$.

\section{EEG Recordings}

A bipolar surface-to-depth electrode was used to record cortical EEG, as described previously (Berridge and Foote, 1996). A screw electrode was placed over the cerebellum and served as ground. The ends of the EEG and screw electrodes were inserted into a five-pin plastic connector. EEG signals were amplified, filtered $(0.3-100.0 \mathrm{~Hz})$, and recorded on a polygraph and VCR recording tape.

\section{Blood Collection and Corticosterone (CORT) Assay}

For Experiment 1b, trunk blood was collected in heparinized tubes and stored temporarily on ice. Plasma was separated by centrifuge within $5 \mathrm{~h}$ and frozen at $-80^{\circ} \mathrm{C}$. CORT was measured using a radioimmunoassay kit (Coata-Count Rat Corticosterone, Diagnostic Products Corporation, Los Angeles, CA, USA). All samples and standards were assayed in duplicate and the average calculated.

\section{Histological Assessment of Infusion Needle and Dialysis Probe Placement}

Following experimental testing, each animal was deeply anesthetized and perfused transcardially with $4 \%$ formaldehyde solution, and the brain was removed, stored in $4 \%$ formaldehyde for $48 \mathrm{~h}$, frozen, and sliced into $50 \mu \mathrm{m}$ sections through the infusion site and, when appropriate, the microdialysis probe implant site. Tissue sections were stained with the Neutral Red dye for subsequent examination of these sites. The presence and extent of the spread of Pontamine Sky Blue dye at the infusion site in freshly sectioned tissue was noted to determine: (i) whether fluid exited the needle; and (ii) the location of the center of the infusion site. The latter was determined primarily to note cases in which the majority of infusate traveled dorsally along the infusion needle, rather than radially from the tip of the infusion needle.

\section{Data Selection Criteria}

Data were included in the analyses only when: (1) histological analyses showed accurate placement of infusion needles, that the infusate entered tissue, and that the majority of the infusate did not travel dorsally along the needle; (2) histological analyses showed accurate placement of dialysis probes; and (3) DA concentrations were stable ( $\pm 10 \%$ of the mean) throughout the baseline portion of the experiment.

\section{Statistical Analyses}

For post-mortem experiments, neurochemical data from each brain region were analyzed using a one-way ANOVA, with two levels of treatment (CeA-AMPA and CeA-vehicle) for Experiment 1a, and three levels of treatment (CeA-
AMPA, CeA-vehicle, and BlA-AMPA) for Experiment $1 \mathrm{~b}$. Right and left PFC data from each experiment were analyzed using a mixed within (hemisphere)/between (treatment)-subjects ANOVA. When statistical significance $(p<0.05)$ was indicated, post hoc analyses were conducted using Tukey's HSD test. In vivo microdialysis data were analyzed using a mixed within (time/sample \#)/between (treatment)-subjects ANOVA. When statistical significance $(p<0.05)$ was indicated, post hoc analyses were conducted using Tukey's HSD test. SPSS 11.0.1 (Chicago, IL, USA) was used for all statistical analyses.

\section{RESULTS}

Experiment 1. Effects of AMPA Infusions within CeA or BlA on Post-Mortem Indices of DA and 5-HT Release

General observations. To assess the extent to which AMPA receptor activation within $\mathrm{CeA}$ alters $\mathrm{DA}$ and/or 5-HT utilization, tissue levels of DA, DOPAC, 5-HT, and 5-HIAA were measured in six brain regions collected $30 \mathrm{~min}$ after AMPA or vehicle infusions. Figure 1a shows a photomicrograph of a typical infusion site. In Experiment 1a, AMPA was administered at a dose of $3.0 \mathrm{ng} / 150 \mathrm{nl} \times 2$ infusions/ hemisphere (total AMPA/hemisphere $=6.0 \mathrm{ng}$ ) using $33 \mathrm{ga}$. infusion needles (see Methods). Histological data indicated that these infusion parameters occasionally resulted in an inadequate spread of infusate radially from the infusion needle tip (in approximately $35 \%$ of cases). In some cases the majority of dye was located dorsal to the tip of the infusion needle, while in other cases, there was a complete absence of dye within the tissue, indicating a failure of infusate to enter the tissue. Previous electrophysiological studies using these infusion volumes and this diameter infusion needle indicate that when either an absence of dye is observed, or the majority of dye is located dorsal to the infusion needle tip, neuronal activity is not altered in the vicinity of the infusion needle tip (Berridge and Foote, 1991; Berridge et al, 1993). Thus, in these cases, animals were excluded from the analyses. In an attempt to render a higher percentage of usable cases, a slightly different set of infusion parameters was chosen for Experiment 1b: infusion volume was $250 \mathrm{nl}(5.0 \mathrm{ng} / 250 \mathrm{nl} \times 2$ infusions/hemisphere, total AMPA/hemisphere $=10 \mathrm{ng}$ ) and $30 \mathrm{ga}$. infusion needles were used. Experiment $1 \mathrm{~b}$ also included a group in which AMPA was infused into BlA (Figure 1b) to assess preliminarily whether BlA-AMPA infusions impact DA and/or 5-HT neurotransmission similar to CeA-AMPA infusions (also see Experiment 2).

In both Experiments 1a and 1b, histological data revealed that some animals that received vehicle infusions within CeA did not have dye present in at least one hemisphere (Experiment 1a, $n=5$; Experiment 1b, $n=4$ ). Statistical analysis revealed that these animals did not differ from vehicle-treated animals with dye present in both hemispheres. For this reason, and because these cases nonetheless provided a control for needle insertion, handling, and infusion procedures, all animals receiving vehicle infusions were included in the analyses.

In both Experiments $1 \mathrm{a}$ and $1 \mathrm{~b}$, the majority of animals were asleep immediately prior to transfer to the infusion chamber. All animals were awake at the time of the 

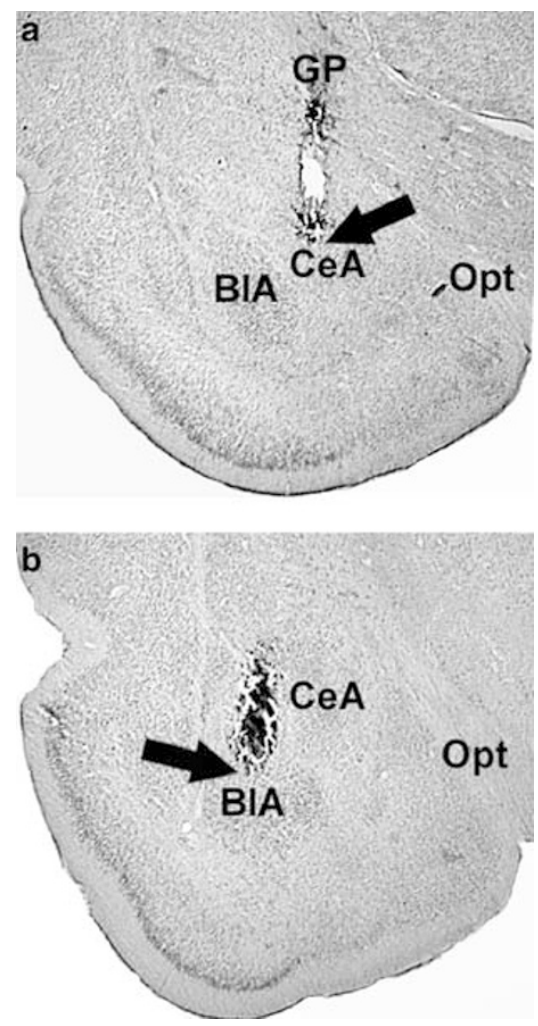

Figure I Photomicrographs of $\mathrm{CeA}$ and BIA infusion sites. Shown are $\mathrm{CeA}(\mathrm{a})$ and BIA (b) infusion sites in Neutral Red-stained coronal sections. Arrows indicate the most ventral extent of each infusion needle track. CeA, central nucleus of the amygdala; BIA, basolateral nucleus of the amygdala; GP, globus pallidus; Opt, optic tract.

infusions due to the infusion procedures (see Methods). Under these conditions, AMPA infusions had no obvious effect on behavior, except perhaps a slight increase in freezing behavior in the CeA-AMPA groups. Abnormal behavior (eg seizure-like) was not observed at any time during or following the infusions. The majority of animals had returned to sleep $30 \mathrm{~min}$ following the infusions, immediately prior to tissue collection.

Effects of AMPA infusions within CeA on DOPAC/DA and 5-HIAA/5-HT ratios. The effects of AMPA infusions within CeA on DOPAC/DA ratios across various brain regions are depicted in Figure 2 (see Table 1 for absolute DA and DOPAC concentrations). Across brain regions, bilateral infusions of AMPA within CeA elicited an activation of DA and 5-HT systems similar to that observed in stress (Dunn and Everitt, 1988; Abercrombie et al, 1989; Bassareo and Di Chiara, 1997; Berridge et al, 1999). Bilateral AMPA infusions within CeA elicited a significant increase in PFC DOPAC/ DA levels (Experiment 1a: $55 \%$ increase, $\mathrm{F}_{1,14}=28.5$, $p<0.001$; Experiment $1 \mathrm{~b}$ : $84 \%$ increase, $\mathrm{F}_{2,17}=38.0$, $p<0.001)$. Previous studies have indicated a possible hemispheric asymmetry in PFC DA release in stress (Berridge et al, 1999). Therefore, in the current studies, left and right PFC hemispheres were analyzed separately. In neither Experiment $1 \mathrm{a}$ nor $1 \mathrm{~b}$ was a significant effect of hemisphere observed within PFC. However, in Experiment $1 \mathrm{a}$, a significant hemisphere $\times$ treatment interaction was observed $\left(\mathrm{F}_{1,14}=6.5, p=0.024\right)$, with a greater increase in

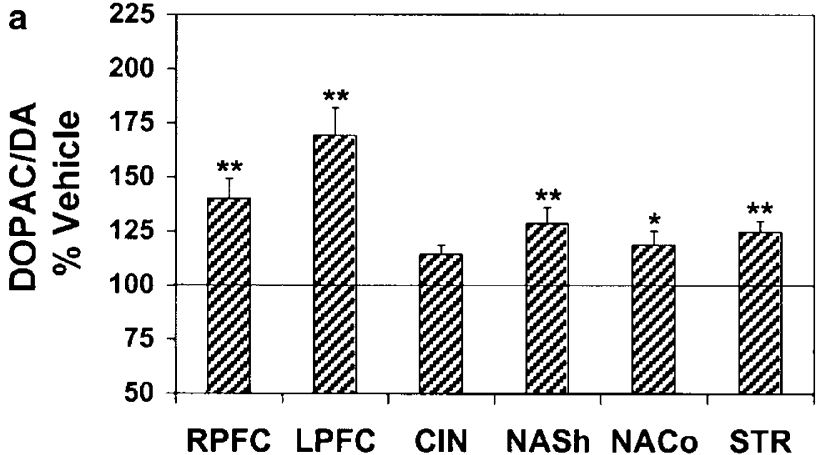

b

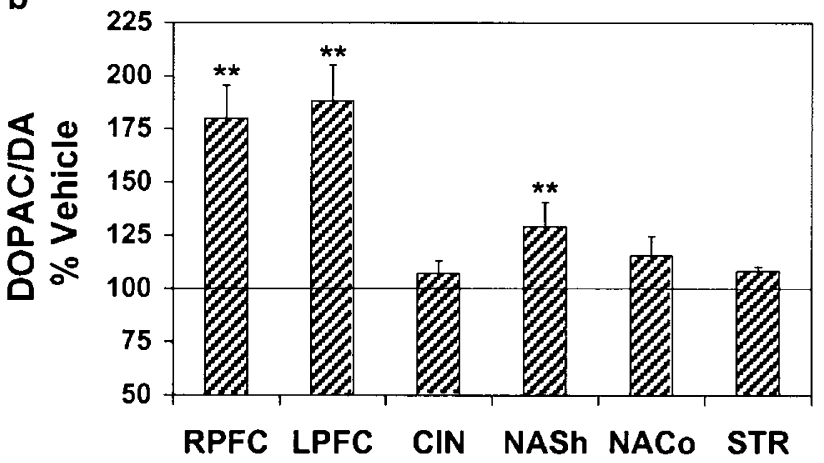

Figure 2 Effects of bilateral AMPA infusion within CeA on DOPAC/DA in right and left prefrontal cortex (RPFC and LPFC), cingulate cortex (CIN), nucleus accumbens shell (NASh), nucleus accumbens core (NACo), and striatum (STR). Top panel (a) displays results from Experiment Ia, in which infusions consisted of $3 \mathrm{ng}$ AMPA per hemisphere. Bottom panel (b) displays results from Experiment $\mathrm{Ib}$, in which infusions consisted of $5 \mathrm{ng}$ AMPA per hemisphere. Shown are mean ( \pm SEM) DOPAC/DA ratios expressed as a percentage of vehicle-treated controls. In both studies, bilateral AMPA infusion within CeA increased DOPAC/DA ratios within LPFC, RPFC, and NASh. Less consistent increases in DOPAC/DA were seen in NACo and STR. ${ }^{*} p<0.05$, ** $p<0.0$ I vs vehicle controls.

DOPAC/DA observed in LPFC in the CeA-AMPA group (LPFC, 69\% increase; RPFC, 40\% increase). In contrast, there was no significant hemisphere $\times$ treatment interaction observed in Experiment $1 \mathrm{~b}\left(\mathrm{~F}_{2,17}=0.3, p=0.76\right.$, LPFC, $88 \%$ increase, RPFC, $80 \%$ increase).

AMPA infusions elicited smaller, although significant, increases in DOPAC/DA within NAcc shell relative to those observed in PFC (Experiment 1a: $29 \%$ increase, $\mathrm{F}_{1,14}=13.0$, $p=0.003$; Experiment $1 \mathrm{~b}: 29 \%$ increase, $\mathrm{F}_{2,18}=5.4$, $p=0.014)$. Although a trend for increased DOPAC/DA was observed within the NAcc core, this was statistically significant in Experiment 1a only (Experiment 1a: 19\% increase, $\mathrm{F}_{1,14}=5.5, p=0.034$; Experiment $1 \mathrm{~b}: 16 \%$ increase $\mathrm{F}_{2,18}=2.1, p=0.150$ ). Similarly, a small increase in DOPAC/ DA was observed within striatum, which was significant in Experiment 1a (24\% increase, $\left.\mathrm{F}_{1,14}=9.5, p=0.008\right)$ but not Experiment $1 \mathrm{~b}\left(8 \%\right.$ increase, $\left.\mathrm{F}_{2,18}=1.7, p=0.22\right)$. AMPA infusions tended to elicit marginal or insignificant increases in DOPAC/DA within the cingulate cortex (Experiment 1a: $14 \%$ increase, $\mathrm{F}_{1,14}=4.6, p=0.05$; Experiment $1 \mathrm{~b}: 7 \%$ increase, $\mathrm{F}_{2,18}=1.7, p=0.21$ ).

To determine the extent to which the above-described effects of AMPA infusions into CeA are specific to DA, the effects of these infusions on 5-HT utilization were also assessed. As shown in Figure 3, bilateral AMPA infusions 
Table I Picogram DA, DOPAC, 5-HT, and 5-HIAA per mg Wet Tissue, and DOPAC/DA and 5-HIAA/5-HT Ratios of CeA-Vehicle and CeA-AMPA Groups

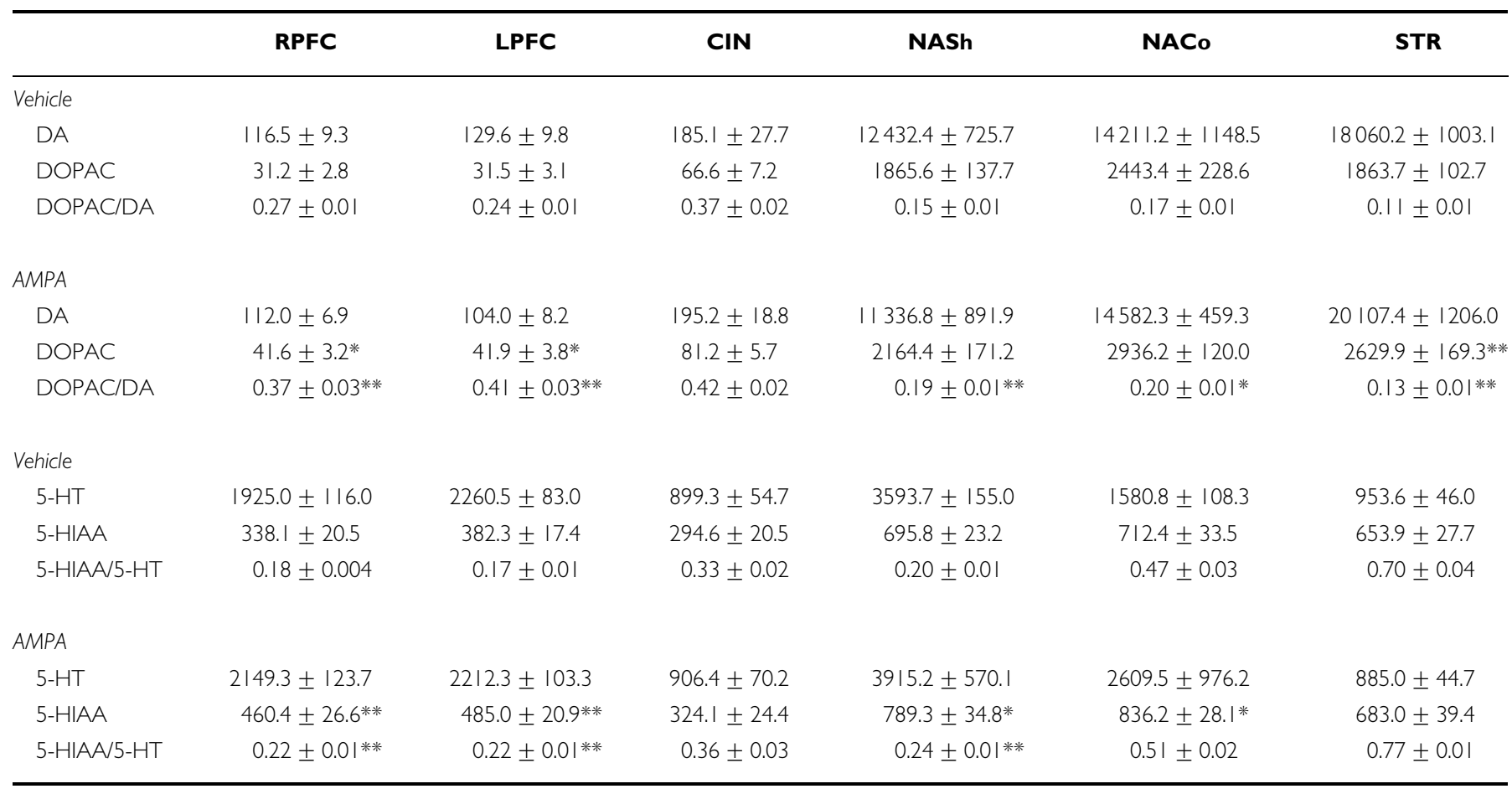

Shown are mean \pm SEM concentrations of DA, DOPAC, 5-HT, and 5-HIAA, as well as DOPAC/DA and 5-HIAA/5-HT ratios in right and left prefrontal cortex (RPFC and LPFC), cingulate cortex (CIN), nucleus accumbens shell and core (NASh and NACo), and dorsal striatum (STR), from CeA-vehicle and CeA-AMPA groups from Experiment la (see Figures $2 \mathrm{a}$ and $3 \mathrm{a}$ ). Data are expressed as $\mathrm{pg} / \mathrm{mg}$ wet weight of tissue. ${ }^{*} p<0.05, * * 0.0 \mathrm{I}$ vs vehicle controls.

into CeA elicited a relatively small increase in 5-HIAA/5-HT within PFC (Experiment 1a: $26 \%$ increase, $\mathrm{F}_{1,14}=26.4$, $p<0.001$; Experiment $1 \mathrm{~b}$ : $13 \%$ increase, $\mathrm{F}_{2,16}=1.3$, $p=0.31$. A more consistent increase in 5-HIAA/5-HT was observed within the NAcc shell (Experiment 1a: 22\% increase, $\mathrm{F}_{1,14}=13.4, p=0.003$; Experiment $1 \mathrm{~b}$ : $42 \%$ increase, $\left.\mathrm{F}_{2,17}=7.4, p=0.005\right)$. AMPA infusions into CeA did not significantly alter indices of 5-HT utilization within any other region examined in either experiment.

Effects of AMPA infusions within BlA on DOPAC/DA and 5-HIAA/5-HT ratios. As described above, Experiment $1 \mathrm{~b}$ included an additional treatment group in which AMPA was infused bilaterally within BlA to provide a preliminary assessment of the extent to which AMPA-induced neuronal activation within BlA alters indices of either DA or 5-HT utilization (also see Experiment 2). As shown in Figure 4, BlA-AMPA infusions did not appear to alter indices of either DA or 5-HT utilization in any brain region examined. Thus, for those regions in which the overall ANOVA indicated a significant effect of treatment on DOPAC/DA (PFC and NAcc shell; see above for F and $p$ values), DOPAC/ DA ratios did not differ significantly between BlA-AMPAtreated animals and CeA-vehicle-treated animals (LPFC, $p=0.973$; RPFC, $p=0.751$; NAcc shell, $p=0.932$ ). Moreover, DOPAC/DA ratios were significantly higher in CeAAMPA-treated animals than in BlA-AMPA-treated animals (LPFC, $p<0.001$; RPFC, $p<0.001$; NAcc shell, $p=0.023$ ).

Similarly, also shown in Figure 4, BlA-AMPA infusions did not impact 5-HIAA/5-HT ratios. Thus, in the only brain region in which there was a significant effect of treatment on 5-HIAA/5-HT (NAcc shell, see above for F and $p$ values), 5-HIAA/5-HT ratios did not differ significantly between BlA-AMPA-treated animals and CeA-vehicle-treated animals $(p=0.964)$, whereas CeA-AMPA-treated animals displayed significantly greater 5-HIAA/5-HT ratios than BlA-AMPA-treated animals $(p=0.017)$.

Effects of AMPA infusions within CeA or BlA on plasma CORT. Plasma CORT levels were measured in animals $30 \mathrm{~min}$ after infusions were made (Experiment $1 \mathrm{~b}$ only). In the CeA-vehicle group, CORT was $104.9 \pm 10.4 \mathrm{ng} / \mathrm{ml}$. AMPA infusions within CeA elicited a large $(162.7 \pm 30.7 \mathrm{ng} / \mathrm{ml} ; 155 \%)$, although nonsignificant, increase in CORT levels, relative to CeA-vehicletreated animals $\left(\mathrm{F}_{2,19}=2.4, p=0.12\right)$. AMPA infusions within BlA did not appear to influence CORT levels $(115.3 \pm 14.3 \mathrm{ng} / \mathrm{ml})$.

\section{Experiment 2. Effects of AMPA Infusions within CeA or BlA on In Vivo Microdialysis Measures of PFC DA Release}

To confirm results obtained with post-mortem measures and to better characterize the time course of AMPA-induced alterations in rates of DA release, the effects of AMPA infusions into $\mathrm{CeA}$ or BlA on extracellular levels of DA in PFC were assessed using in vivo microdialysis. These studies utilized the same infusion protocol used in Experiment $1 \mathrm{~b}$, except infusions were controlled remotely and performed at a time when animals were asleep. Previous work indicates an arousal-enhancing action of 

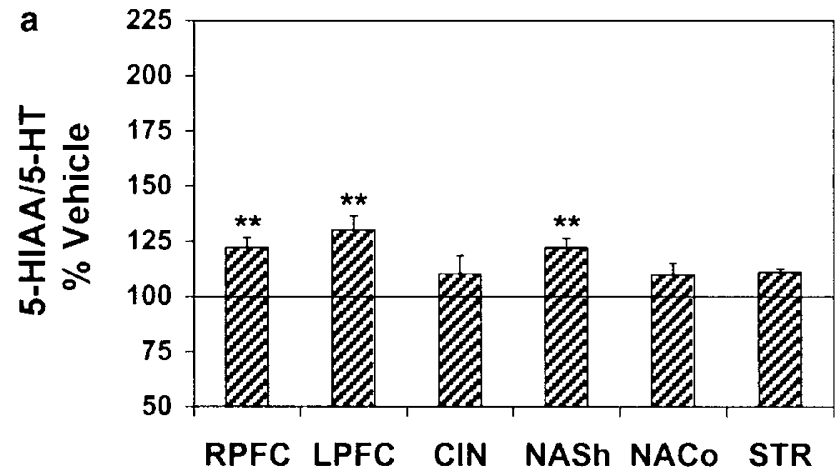

b

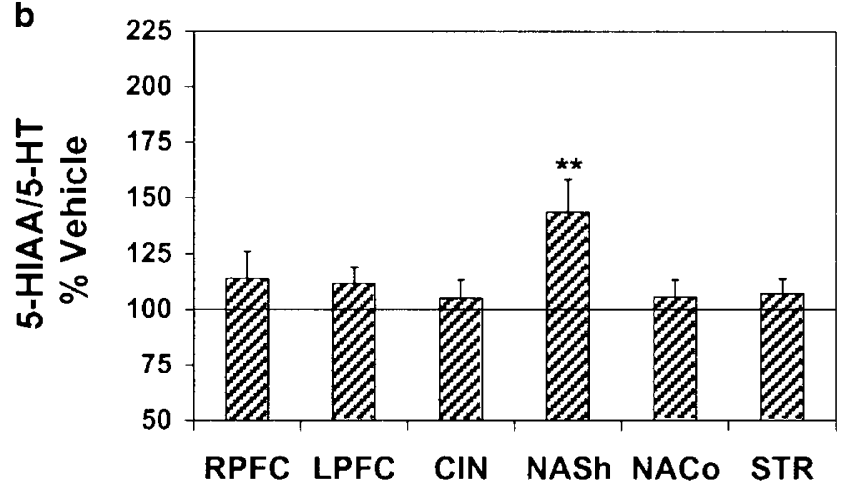

Figure 3 Effects of bilateral AMPA infusion within CeA on 5-HIAA/5-HT in RPFC and LPFC, CIN, NASh, NACo, and STR. Shown are results from Experiment Ia (a) and Experiment Ib (b). Shown are mean ( \pm SEM) 5 HIAA/5-HT ratios expressed as a percentage of vehicle-treated controls. Bilateral AMPA infusion within CeA consistently increased 5-HIAA/5-HT ratios within NASh and less consistently increased 5-HIAA/5-HT ratios within RPFC and LPFC. $* p<0.05$, *** $p<0.0$ I vs vehicle controls.

CeA activation (Kapp et al, 1994). The extent to which CeAAMPA receptor activation enhances arousal has not been examined. As a preliminary exploration of this issue and to assess the relationship between AMPA-induced increases in DA release and arousal, behavioral indices of sleep and waking were recorded in all animals throughout the experiment. In a subset of these animals, EEG was also recorded. As in Experiment 1, AMPA infusions into CeA, $\mathrm{BlA}$, or adjacent regions did not elicit atypical behavior.

Effects of AMPA infusions into CeA or BlA on extracellular DA levels within PFC. Figure 5 displays the effects of AMPA infusions into CeA and BlA on extracellular DA levels within PFC. Baseline averages of extracellular DA were $0.83 \pm 0.10 \mathrm{pg} / 20 \mu \mathrm{l}$ dialysate for the vehicle group, $0.70 \pm 0.06 \mathrm{pg} / 20 \mu \mathrm{l}$ dialysate for the CeA-AMPA group, and $0.87 \pm 0.23 \mathrm{pg} / 20 \mu \mathrm{l}$ dialysate for the BlA-AMPA group. Infusions were performed during the first $4 \mathrm{~min}$ of the first 16-min post-infusion sample. Statistical analyses revealed a significant effect of treatment $\left(\mathrm{F}_{2,17}=3.7, p=0.048\right)$, but not of time $\left(\mathrm{F}_{5,85}=2.0, p=0.08\right)$ or treatment $\times$ time $\left(\mathrm{F}_{10,85}=\right.$ $1.3, p=0.25)$. Post hoc analyses indicated that the CeAAMPA group differed from the CeA-vehicle group only at the first post-infusion time point $(p=0.03)$, when CeA-AMPA DA levels were $143 \%$ of baseline. The BlA-AMPA group did not differ from the CeA-vehicle group at any time point.

Within CeA-AMPA-treated animals, left and right PFC DA responses appeared comparable (data not shown).
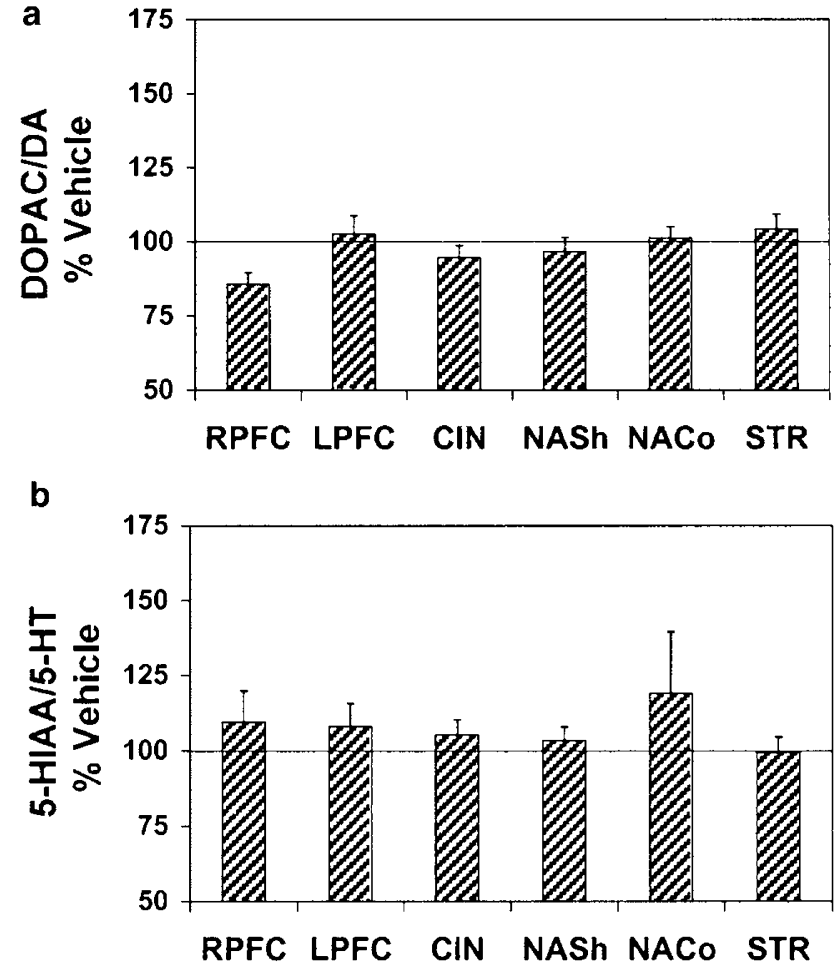

Figure 4 Effects of bilateral AMPA infusion within BIA on DOPAC/DA (a) and 5-HIAA/5-HT (b) in RPFC and LPFC, CIN, NASh, NACo, and STR. Data are from Experiment $\mathrm{lb}$, in which $5 \mathrm{ng}$ AMPA was infused per hemisphere. Shown are mean ( \pm SEM) DOPAC/DA or 5-HIAA/5-HT ratios expressed as a percentage of CeA-vehicle-treated controls. In contrast to results observed with infusion within $\mathrm{CeA}$, bilateral AMPA infusion within BIA did not elicit consistent alterations in either DOPAC/ DA or 5-HIAA/5-HT within any region examined. $* p<0.05$, $* * * 0.0$ I vs vehicle controls.

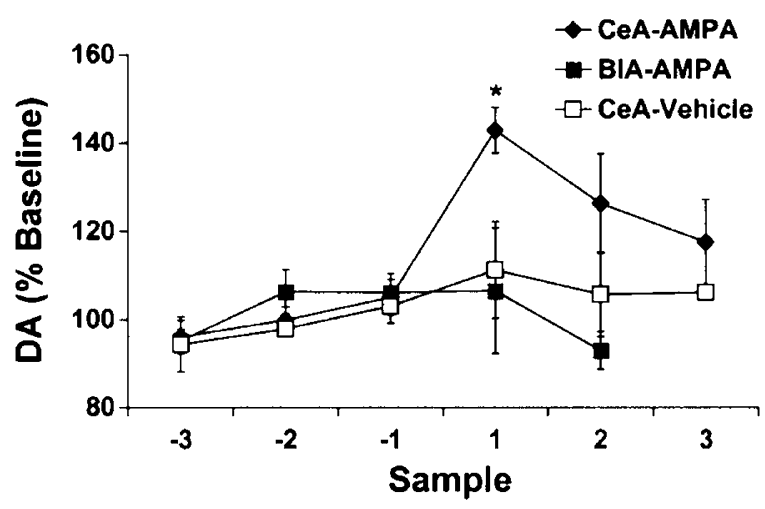

Figure 5 Effects of bilateral infusion of vehicle or AMPA within CeA or bilateral AMPA infusion within BIA on extracellular DA levels as measured by in vivo microdialysis. Shown are mean $( \pm$ SEM) expressed as a percentage of baseline levels for consecutive 16-min samples. Infusions were made immediately following sample $\#-1$, during the first 4 min of sample $\# I$. Bilateral AMPA infusion within $\mathrm{CeA}$, but not BIA, elicited a substantial increase in DA levels within PFC during the first post-infusion sample. ${ }^{*} p<0.05$ vs CeA-vehicle.

Within this group, the maximal increase in extracellular DA was generally confined to the first post-infusion sample. Lower levels that remained elevated compared to baseline levels were observed in the second post-infusion sample in approximately $50 \%$ of cases. This relatively short-lived 
increase in DA levels is consistent with electrophysiological observations in pilot studies described above (see Methods). However, in a limited number of cases $(n=4)$, nearmaximal DA levels were sustained beyond the first postinfusion sample into post-infusion samples 3 or 4 . In these cases, animals also displayed a longer behavioral response (waking) to the AMPA infusions.

Following the return of extracellular DA levels to baseline values, most animals were picked up repeatedly over a 60 -s period to elicit a relatively high-arousal state (ie handlingstress). This manipulation resulted in a robust increase in PFC extracellular DA levels $(n=20$, mean $=148 \%$ of baseline). This magnitude increase in DA levels within PFC is comparable to that described previously with other stressors (Abercrombie et al, 1989).

Effects of AMPA infusions within CeA or BlA on behavioral and EEG measures of sleep and waking. Behavior was videotaped in all animals used in the microdialysis studies. All animals appeared asleep on the basis of behavioral measures at the time of the infusion (ie body and head on the floor). Following bilateral CeA-AMPA infusions, 11 out of 13 animals woke up (head raised off the floor) within the first $4 \mathrm{~min}$ following the start of the infusions (approximately corresponding to the most robust period of neuronal activation as determined in pilot studies; see Methods). Latency to waking was $102 \pm 20 \mathrm{~s}$ (range $=22-225 \mathrm{~s}$ ) with an average duration of $526 \pm 69 \mathrm{~s}$. In contrast to AMPA-treated animals, only one out of four vehicle-treated animals displayed a brief bout of waking in the same period of time following the start of the infusions (latency $=58 \mathrm{~s}$, duration $=18 \mathrm{~s}$ ).

A subset of animals was implanted with a cortical EEG electrode $(n=5)$ to better characterize the time course of the wake-promoting actions of CeA-AMPA infusions. At the start of the infusion, all animals displayed large-amplitude, low-frequency activity indicative of slow-wave sleep (see Figure 6). In all cases, AMPA infusions within CeA elicited a rapid activation of cortical EEG characterized by the appearance of low-voltage, high-frequency activity. AMPA-induced EEG activation occurred with a mean latency of $75 \pm 31 \mathrm{~s}$ (range $=31-195)$ from the beginning of the first 60-s infusion (see Figure 6) and a duration of $820 \pm 100 \mathrm{~s}$ (range $=600-1078$ ). In contrast, although EEG activation was observed in some of the vehicle-treated animals, it occurred with a substantially longer latency $(166 \pm 60$, range $=56-321 \mathrm{~s})$ and a substantially shorter duration (77 $\pm 43 \mathrm{~s}$, range $28-204 \mathrm{~s}$ ) than that observed in AMPA-treated animals. Interestingly, although BlA-AMPA infusions did not elicit an increase in DA efflux, these infusions $(n=3)$ did appear to elicit a moderate increase in waking based on either behavioral (latency $=134 \pm 47$, duration $=68 \pm 22$ ) or EEG measures (latency $=42 \pm 10$, duration $=348 \pm 30$ ).

\section{Effects of Unilateral AMPA Infusions within CeA or Bilateral AMPA Infusions Dorsal to CeA on Indices of DA Release}

In some cases in Experiments $1 \mathrm{a}$ and $1 \mathrm{~b}$, histological data indicated that inaccurate needle-tip placement or inade-

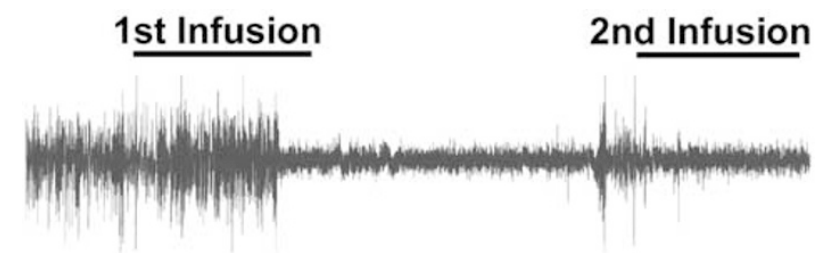

Figure 6 Effects of bilateral infusion of AMPA within CeA on cortical EEG. The dose of AMPA was $5.0 \mathrm{ng} /$ infusion/hemisphere. Shown is a 5-min EEG trace before and during infusions. Bars denote time of infusions. Prior to the infusions, the animal spent the majority of time in slow-wave sleep, characterized by large-amplitude, slow-wave EEG activity. CeA-AMPA infusion elicited a short-latency desynchronization of EEG that persisted, in this case, for approximately $10 \mathrm{~min}$

quate spread of infusate radially from the infusion needletip occurred in one or both hemispheres. In one case from Experiment 1a, bilateral AMPA infusions were made within the globus pallidus, dorsal to CeA. In another case, from Experiment 1b, AMPA infusions were made within the substantia innominata immediately dorsal to $\mathrm{CeA}$ in the left hemisphere and within CeA in the right hemisphere. In both of these cases, DOPAC/DA ratios in all brain regions in which they were measured were well within the range of vehicle-infused animals. In addition, in Experiment 2, bilateral AMPA infusions immediately dorsal to $\mathrm{CeA}$ were intentionally made in two cases. In neither of these cases did PFC DA levels increase above baseline levels. Combined, these observations indicate that neither infusions dorsal to $\mathrm{CeA}$ nor infusions lateral to $\mathrm{CeA}$ (ie within BlA) alter indices of DA utilization.

There were also several cases in Experiment $1 \mathrm{~b}$ in which unilateral AMPA infusions were made within CeA, and an absence of dye was observed within the contralateral hemisphere (unilateral left CeA-AMPA, $n=5$; unilateral right CeA-AMPA, $n=3$ ). Analyses of these cases indicated that neither left unilateral nor right unilateral CeA-AMPA infusions resulted in DOPAC/DA or 5-HIAA/5-HT ratios outside of the range of vehicle-treated animals (data not shown). In addition, in several cases in Experiment 2, unilateral AMPA infusions within CeA (right CeA $n=2$, left CeA $n=3$ ) were made intentionally. In none of these cases were DA levels altered from baseline.

\section{DISCUSSION}

The current studies demonstrate that stimulation of AMPA receptors within CeA results in a differential activation of dopaminergic efferents across cortical and subcortical terminal fields. Thus, AMPA infusions within CeA elicited a relatively large increase in DA utilization within PFC, smaller increases within the NAcc shell, and even smaller and less consistent increases within the NAcc core and dorsal striatum. This pattern of activation of DA efferents is similar to that observed in high-arousal states such as stress and reward (Dunn and Everitt, 1988; Abercrombie et al, 1989; Bassareo and Di Chiara, 1997; Berridge et al, 1999; Cousins et al, 1999). Activation of CeA-AMPA receptors also elicited smaller and stress-like (Berridge et al, 1999) increases in 5-HT utilization in PFC and accumbens shell as well as an increase in plasma CORT levels. When infusions were made into sleeping animals, the AMPA-induced 
activation of DA and 5-HT systems was accompanied by a rapid transition from the sleeping to the waking state. Importantly, infusions outside of $\mathrm{CeA}$, including within $\mathrm{BlA}$, did not alter indices of DA or 5-HT neurotransmission. The current results extend previous observations indicating that lesions of CeA suppress stressor-induced activation of DA and 5-HT neurotransmitter systems (Davis et al, 1994; Goldstein et al, 1996) by demonstrating that (1) increased CeA neuronal activity is sufficient to elicit stress- and/or reward-like activation of these two neurotransmitter systems and, more specifically (2) CeA-AMPA receptors may play a role in these actions. Combined, these observations suggest a critical role of $\mathrm{CeA}$ in the regulation of DA and 5-HT neurotransmission in moderate-to-high arousal conditions.

\section{Methodological Considerations}

The current studies used both post-mortem- and microdialysis-based measures of DA neurotransmission. Postmortem measures permit simultaneous examination of multiple DA and 5-HT terminal fields. Microdialysis permits the verification of alterations in extracellular levels of a given neurotransmitter as well as characterization of the time course of these alterations within a limited set of terminal fields. Post-mortem measures based on DOPAC/ DA ratios reduce variability resulting from individual differences in tissue levels of DA and have been demonstrated to reflect alterations in DA neuronal discharge rates (Elchisak et al, 1976; Roth et al, 1976; Wood and Altar, 1988). Importantly, post-mortem measures have been demonstrated to provide results similar to those obtained with in vivo microdialysis-based measures of rates of DA neurotransmission in stress (Dunn and Everitt, 1988; Roth et al, 1988; Abercrombie et al, 1989). The only conditions under which DOPAC/DA ratios do not accurately reflect alterations in DA release occur following pharmacological manipulations that bypass normal physiological mechanisms regulating neurotransmitter release and metabolism (eg amphetamine, uptake blockers, MAO inhibitors; Roth et al, 1973, 1976; Kuczenski, 1983). Finally, results obtained in the current microdialysis studies (Experiment 2) provide evidence that the increases in DOPAC/DA ratios observed in the current post-mortem experiments (Experiment 1a/ 1b) reflect increases in extracellular DA levels.

The current studies utilized chemical stimulation to examine the consequences of acute neuronal activation within $\mathrm{CeA}$ and $\mathrm{BlA}$ on rates of $\mathrm{DA}$ neurotransmission. An advantage of this approach, as opposed to electrical stimulation, is that it avoids activation of fibers of passage and is dependent on physiologically relevant, receptormediated processes. In pilot studies, local AMPA infusions, using similar infusion parameters, resulted in a sustained increase in LC neuronal activity when the infusion needle was placed $\sim 200-400 \mu \mathrm{m}$ from the recording electrode. In these pilot studies, neuronal activity returned to baseline discharge levels following the infusion, and neuronal activation was elicited with repeated infusions (see Methods for further description). Combined, these results provide evidence that, at the dose and volume used in the current studies, AMPA infusions increased neuronal activity within the immediate vicinity of the infusion needle without eliciting an over-activation of neuronal discharge rate (ie depolarization block) or damaging neurons in the vicinity of the infusion needle (ie excitotoxicity).

\section{CeA and Arousal}

Previous work has demonstrated increases in EEG indices of arousal following electrical stimulation of the CeA (Kapp et al, 1994). The current findings demonstrate a similar activation of forebrain EEG following AMPA-induced activation of CeA. Additionally, these studies demonstrate that increases in DA release observed following CeA-AMPA infusions follow a time course that is largely similar to that observed for CeA-dependent activation of forebrain EEG. Available evidence suggests that activation of dopaminergic systems may be associated with waking (Monti et al, 1989, 1990; Trampus et al, 1991, 1993). Combined, these observations suggest a potential role of CeA-dependent activation of DA systems in the arousal-modulating actions of CeA.

Both 5-HT and acetylcholine have been implicated in the regulation of EEG activity state (Vanderwolf and Robinson, 1981; Jacobs et al, 1990; Kapp et al, 1994). The current studies demonstrate increased rates of 5-HT release following AMPA infusions into CeA. Additionally, previous work demonstrates that activation of EEG following electrical stimulation of $\mathrm{CeA}$ is blocked by cholinergic antagonists (Kapp et al, 1994). Thus, these observations suggest the CeA coordinates the activation of multiple ascending neuronal systems that participate in the regulation of behavioral state. Related to this, available evidence suggests CeA may modulate LC discharge activity (Van Bockstaele et al, 1998). Moreover, the LC-noradrenergic system has been demonstrated to exert wake-promoting actions (Berridge and Foote, 1991, 1996; Berridge et al, 1996). Thus, it might be predicted that AMPA-induced activation of CeA will also elicit an activation of the LC-noradrenergic system.

Given that rates of DA neurotransmission may be statedependent, it is possible that increased rates of DA release elicited by AMPA infusions are an indirect consequence of the induction of the waking or aroused state. Arguing against this hypothesis are two observations. First, in the studies utilizing post-mortem measures, all infusions were performed in animals that were awake at the time of the infusion, and the majority of animals, regardless of treatment condition, were asleep immediately prior to tissue collection. Thus, under these conditions AMPA infusions did not change the sleep/wake state of the animal relative to vehicletreated animals. Nonetheless, in these studies, CeA-AMPA infusions resulted in a substantial increase in indices of DA neurotransmission. Second, in the above-described studies utilizing in vivo microdialysis, bilateral CeA-AMPA infusions elicited quiet, and not active, waking. Previous studies demonstrate that quiet waking is associated with a relatively small increase in DA levels within PFC (eg approximately 25\%; Berridge and Stalnaker, 2002), well below the magnitude of the DA response observed following AMPA infusions within $\mathrm{CeA}$ in the current studies.

\section{Site of Action}

The current studies suggest $\mathrm{CeA}$ is the critical site of action for the AMPA-induced neurochemical changes described 
above. Thus, infusions made either dorsal to CeA within substantia innominata or globus pallidus, or lateral to $\mathrm{CeA}$ within $\mathrm{BlA}$, did not result in any changes in DA or 5-HT neurotransmission. These results are consistent with recent observations demonstrating that lidocaine injections within $\mathrm{CeA}$ attenuate reward-related increases in DA release within NAcc, whereas lidocaine injections within BlA do not attenuate such increases in DA neurotransmission (Ahn and Phillips, 2003). However, the current results are in seeming conflict with previous work demonstrating that electrical stimulation of BlA increases DA release within PFC and NAcc (Floresco et al, 1998; Jackson and Moghaddam, 2001; Howland et al, 2002). There are several possible reasons for this apparent discrepancy. First, AMPA receptor activation may impact only a subset of BlA neurons. Thus, it is possible that stimulation of AMPA receptors within BlA does not target those neurons which are activated by electrical stimulation and influence dopaminergic neurotransmission. Second, electrical stimulation may activate fibers of passage that drive DA neurotransmission. Finally, electrical stimulation at parameters in the same general range as those used in these previous studies can produce either focal or generalized seizures (Goddard et al, 1969; Cain and Corcoran, 1981). These seizures have been elicited with as few as a single episode of stimulation and could increase DA release through a generalized stress response.

In addition to demonstrating a role of $\mathrm{CeA}$ in monoaminergic neurotransmission and arousal, the current observations further suggest a critical role of AMPA receptors in these actions. In particular, these observations indicate that CeA-AMPA receptors exert a robust stimulatory action on DA neurotransmission, particularly within PFC, in addition to changing behavioral state. CeA-AMPA receptors have been previously implicated in both the acquisition and expression of fear-potentiated startle (Walker and Davis, 1997, 2002). The current observations suggest the hypothesis that CeA-AMPA receptors contribute to increased rates of DA and 5-HT efflux within PFC and other dopaminergic terminal fields in aversive and/or appetitive environmental conditions.

\section{Circuitry Underlying CeA-AMPA-Induced Activation of} Monoaminergic Systems

The circuitry through which CeA influences DA and 5-HT neurotransmission, as well as CORT secretion, is currently unknown. Previous reports suggest a direct projection from $\mathrm{CeA}$ to midbrain dopaminergic nuclei, including both the substantia nigra and the ventral tegmental area (VTA) (Price and Amaral, 1981; Gonzales and Chesselet, 1990; Wallace et al, 1992). However, it should be noted that recent studies have failed to find evidence of a direct projection from CeA to VTA (Zahm et al, 1999; Fadel et al, 2001). Another possibility is that $\mathrm{CeA}$ influences dopamine neurotransmission via a multisynaptic pathway to dopaminergic cell bodies. For example, there exists an extensive projection from $\mathrm{CeA}$ to the posterior lateral hypothalamus (Gonzales and Chesselet, 1990; Krettek and Price, 1978; Price and Amaral, 1981; Zahm et al, 1999; Petrovich et al, 2001), which in turn projects to VTA (Phillipson, 1979; Hosoya and Matsushita, 1981; Berk and Finkelstein, 1982). Similarly, CeA could influence serotonergic neuronal activity via either a direct projection to the dorsal raphe nucleus (Price and Amaral, 1981; Peyron et al, 1998) or a multisynaptic pathway, possibly through the lateral hypothalamus (Behzadi et al, 1990; Peyron et al, 1998; Hosoya and Matsushita, 1981; Berk and Finkelstein, 1982). Finally, a projection from $\mathrm{CeA}$ to the paraventricular nucleus of the hypothalamus has been described, through which CeA could influence CORT secretion (Gray et al, 1989; Marcilhac and Siaud, 1997; Prewitt and Herman, 1998).

An asymmetrical activation of PFC DA efferents has often been observed in stress (Carlson et al, 1993; Sullivan and Gratton, 1998; Berridge et al, 1999). For example, noveltystress elicits a greater increase in DOPAC/DA levels within the right hemisphere PFC than that observed within the left hemisphere (Berridge et al, 1999). Currently, the neural basis for asymmetrical DA release within PFC in stress remains unclear. Evidence from the present study suggests that this asymmetrical activation of PFC DA efferents in stress does not involve actions of the CeA. First, bilateral AMPA infusion within CeA elicited comparable activation of right and left PFC DA efferents. Second, unilateral AMPA infusions did not impact indices of DA release within either hemisphere of PFC.

\section{Conclusions}

Recent work suggests a broad modulatory action of the CeA on a variety of cognitive processes under conditions in which information collection is essential (Gallagher and Holland, 1994; Whalen, 1998; Holland et al, 2000). Similarly, extensive evidence indicates a critical role of DA (and to a lesser extent 5-HT) in a variety of cognitive and affective processes under both appetitive and aversive high-arousal conditions (Wise and Rompre, 1989; Salamone, 1994; Williams and Goldman-Rakic, 1995; Arnsten, 1997; Schultz, 1998; Lucki, 1998; Smith-Roe and Kelley, 2000; Baldwin et al, 2002). The current studies suggest CeA-dependent activation of dopaminergic and serotonergic systems may contribute to optimal behavioral responsiveness and plasticity associated with both appetitive and aversive high-arousal conditions.

\section{ACKNOWLEDGEMENTS}

We gratefully acknowledge the assistance of Dr Ned Kalin in carrying out corticosterone measurements. This work was supported in part by The University of Wisconsin Graduate School, and PHS Grants DA10681(KO2) and MH18931.

\section{REFERENCES}

Abercrombie ED, Keefe KA, DiFrischia DS, Zigmond MJ (1989). Differential effect of stress on in vivo dopamine release in striatum, nucleus accumbens, and medial frontal cortex. J Neurochem 52: 1655-1658.

Ahn S, Phillips AG (1999). Dopaminergic correlates of sensoryspecific satiety in the medial prefrontal cortex and nucleus accumbens of the rat. J Neurosci 19: RC29.

Ahn S, Phillips AG (2003). Independent modulation of basal and feeding-evoked dopamine efflux in the nucleus accumbens and medial prefrontal cortex by the central and basolateral amygdalar nuclei in the rat. Neuroscience 116: 295-305.

Arnsten AF (1997). Catecholamine regulation of the prefrontal cortex. J Psychopharmacol 11: 151-162. 
Baldwin AE, Sadeghian K, Kelley AE (2002). Appetitive instrumental learning requires coincident activation of NMDA and dopamine D1 receptors within the medial prefrontal cortex. J Neurosci 22: 1063-1071.

Bassareo V, Di Chiara G (1997). Differential influence of associative and nonassociative learning mechanisms on the responsiveness of prefrontal and accumbal dopamine transmission to food stimuli in rats fed ad libitum. J Neurosci 17: 851-861.

Behzadi G, Kalen P, Parvopassu F, Wiklund L (1990). Afferents to the median raphe nucleus of the rat: retrograde cholera toxin and wheat germ conjugated horseradish peroxidase tracing, and selective $\mathrm{D}-\left[{ }^{3} \mathrm{H}\right]$ aspartate labelling of possible excitatory amino acid inputs. Neuroscience 37: 77-100.

Berk ML, Finkelstein JA (1982). Efferent connections of the lateral hypothalamic area of the rat: an autoradiographic investigation. Brain Res Bull 8: 511-526.

Berridge CW, Abercrombie ED (1999). Relationship between locus coeruleus discharge rates and rates of norepinephrine release within neocortex as assessed by in vivo microdialysis. Neuroscience 93: 1263-1270.

Berridge CW, Bolen SJ, Manley MS, Foote SL (1996). Modulation of forebrain electroencephalographic activity in halothane-anesthetized rat via actions of noradrenergic beta-receptors within the medial septal region. J Neurosci 16: 7010-7020.

Berridge CW, Foote SL (1991). Effects of locus coeruleus activation on electroencephalographic activity in neocortex and hippocampus. J Neurosci 11: 3135-3145.

Berridge CW, Foote SL (1996). Enhancement of behavioral and electroencephalographic indices of waking following stimulation of noradrenergic beta-receptors within the medial septal region of the basal forebrain. J Neurosci 16: 6999-7009.

Berridge CW, Mitton E, Clark W, Roth RH (1999). Engagement in a non-escape (displacement) behavior elicits a selective and lateralized suppression of frontal cortical dopaminergic utilization in stress. Synapse 32: 187-197.

Berridge CW, Page ME, Valentino RJ, Foote SL (1993). Effects of locus coeruleus inactivation on electroencephalographic activity in neocortex and hippocampus. Neuroscience 55: 381-393.

Berridge CW, Stalnaker TA (2002). Relationship between low-dose amphetamine-induced arousal and extracellular norepinephrine and dopamine levels within prefrontal cortex. Synapse 46: 140-149.

Cain DP, Corcoran ME (1981). Kindling with low-frequency stimulation: generality, transfer, and recruiting effects. Exp Neurol 73: 219-232.

Cardinal RN, Parkinson JA, Hall J, Everitt BJ (2002). Emotion and motivation: the role of the amygdala, ventral striatum, and prefrontal cortex. Neurosci Biobehav Rev 26: 321-352.

Carlson JN, Fitzgerald LW, Keller Jr RW, Glick SD (1993). Lateralized changes in prefrontal cortical dopamine activity induced by controllable and uncontrollable stress in the rat. Brain Res 630: 178-187.

Cousins MS, Trevitt J, Atherton A, Salamone JD (1999). Different behavioral functions of dopamine in the nucleus accumbens and ventrolateral striatum: a microdialysis and behavioral investigation. Neuroscience 91: 925-934.

Davis M (2000). The role of the amygdala in conditioned and unconditioned fear and anxiety. In: Aggleton JP (ed). The Amygdala. Oxford University Press: Oxford, UK. pp 213-287.

Davis M, Hitchcock JM, Bowers MB, Berridge CW, Melia KR, Roth RH (1994). Stress-induced activation of prefrontal cortex dopamine turnover: blockade by lesions of the amygdala. Brain Res 664: 207-210.

Dunn LT, Everitt BJ (1988). Double dissociations of the effects of amygdala and insular cortex lesions on conditioned taste aversion, passive avoidance, and neophobia in the rat using the excitotoxin ibotenic acid. Behav Neurosci 102: 3-23.

Dunn AJ, File SE (1983). Cold restraint alters dopamine metabolism in frontal cortex, nucleus accumbens and neostriatum. Physiol Behav 31: 511-513.

Elchisak MA, Murrin LC, Roth RH, Maas JW (1976). Free and conjugated dihydroxyphenylacetic acid: effect of alterations in impulse flow in rat neostriatum and frontal cortex. Psychopharmacol Commun 2: 411-420.

Fadel J, Deutch AY (2002). Anatomical substrates of orexindopamine interactions: lateral hypothalamic projections to the ventral tegmental area. Neuroscience 111: 379-387.

Fadel J, Zahm DH, Deutch AY (2001). Amygdala projections to the lateral hypothalamus: relationship to cells retrogradely labeled from the ventral tegmental area. Soc Neurosci Abstr 27, 68.14 .

Fiorino DF, Coury A, Phillips AG (1997). Dynamic changes in nucleus accumbens dopamine efflux during the Coolidge effect in male rats. J Neurosci 17: 4849-4855.

Floresco SB, Yang CR, Phillips AG, Blaha CD (1998). Basolateral amygdala stimulation evokes glutamate receptor-dependent dopamine efflux in the nucleus accumbens of the anaesthetized rat. Eur J Neurosci 10: 1241-1251.

Gallagher M, Chiba AA (1996). The amygdala and emotion. Curr Opin Neurobiol 6: 221-227.

Gallagher M, Holland PC (1994). The amygdala complex: multiple roles in associative learning and attention. Proc Natl Acad Sci USA 91: 11771-11776.

Goddard GV, McIntyre DC, Leech CK (1969). A permanent change in brain function resulting from daily electrical stimulation. Exp Neurol 25: 295-330.

Goldstein LE, Rasmusson AM, Bunney BS, Roth RH (1996). Role of the amygdala in the coordination of behavioral, neuroendocrine, and prefrontal cortical monoamine responses to psychological stress in the rat. J Neurosci 16: 4787-4798.

Gonzales C, Chesselet MF (1990). Amygdalonigral pathway: an anterograde study in the rat with Phaseolus vulgaris leucoagglutinin (PHA-L). J Comp Neurol 297: 182-200.

Gray TS, Carney ME, Magnuson DJ (1989). Direct projections from the central amygdaloid nucleus to the hypothalamic paraventricular nucleus: possible role in stress-induced adrenocorticotropin release. Neuroendocrinology 50: 433-446.

Holland PC, Han JS, Gallagher M (2000). Lesions of the amygdala central nucleus alter performance on a selective attention task. J Neurosci 20: 6701-6706.

Hosoya Y, Matsushita M (1981). Brainstem projections from the lateral hypothalamic area in the rat, as studied with autoradiography. Neurosci Lett 24: 111-116.

Howland JG, Taepavarapruk P, Phillips AG (2002). Glutamate receptor-dependent modulation of dopamine efflux in the nucleus accumbens by basolateral, but not central, nucleus of the amygdala in rats. J Neurosci 22: 1137-1145.

Jackson ME, Moghaddam B (2001). Amygdala regulation of nucleus accumbens dopamine output is governed by the prefrontal cortex. J Neurosci 21: 676-681.

Jacobs BL, Wilkinson LO, Fornal CA (1990). The role of brain serotonin. A neurophysiologic perspective. Neuropsychopharmacology 3: 473-479.

Kapp BS, Supple Jr WF, Whalen PJ (1994). Effects of electrical stimulation of the amygdaloid central nucleus on neocortical arousal in the rabbit. Behav Neurosci 108: 81-93.

Kim M, Campeau S, Falls WA, Davis M (1993). Infusion of the nonNMDA receptor antagonist CNQX into the amygdala blocks the expression of fear-potentiated startle. Behav Neural Biol 59: 5-8.

Krettek JE, Price JL (1978). Amygdaloid projections to subcortical structures within the basal forebrain and brainstem in the rat and cat. J Comp Neurol 178: 225-254. 
Kuczenski R (1983). Biochemical actions of amphetamine and other stimulants. In: Creese I (ed). Stimulants: Neurochemical, Biochemical, and Clinical Perspectives. Raven Press: New York. pp 31-61.

LeDoux JE (2000). Emotion circuits in the brain. Annu Rev Neurosci 23: 155-184.

Lucki I (1998). The spectrum of behaviors influenced by serotonin. Biol Psychiatry 44: 151-162.

Marcilhac A, Siaud P (1997). Identification of projections from the central nucleus of the amygdala to the paraventricular nucleus of the hypothalamus which are immunoreactive for corticotrophinreleasing hormone in the rat. Exp Physiol 82: 273-281.

Monti JM, Fernandez M, Jantos H (1990). Sleep during acute dopamine D1 agonist SKF 38393 or D1 antagonist SCH 23390 administration in rats. Neuropsychopharmacology 3: 153-162.

Monti JM, Jantos H, Fernandez M (1989). Effects of the selective dopamine D-2 receptor agonist, quinpirole on sleep and wakefulness in the rat. Eur J Pharmacol 169: 61-66.

Parkinson JA, Robbins TW, Everitt BJ (2000). Dissociable roles of the central and basolateral amygdala in appetitive emotional learning. Eur J Neurosci 12: 405-413.

Pascoe JP, Kapp BS (1985). Electrophysiological characteristics of amygdaloid central nucleus neurons during Pavlovian fear conditioning in the rabbit. Behav Brain Res 16: 117-133.

Petrovich GD, Canteras NS, Swanson LW (2001). Combinatorial amygdalar inputs to hippocampal domains and hypothalamic behavior systems. Brain Res Brain Res Rev 38: 247-289.

Peyron C, Petit JM, Rampon C, Jouvet M, Luppi PH (1998). Forebrain afferents to the rat dorsal raphe nucleus demonstrated by retrograde and anterograde tracing methods. Neuroscience 82: 443-468.

Phillipson OT (1979). Afferent projections to the ventral tegmental area of Tsai and interfascicular nucleus: a horseradish peroxidase study in the rat. J Comp Neurol 187: 117-143.

Prewitt CM, Herman JP (1998). Anatomical interactions between the central amygdaloid nucleus and the hypothalamic paraventricular nucleus of the rat: a dual tract-tracing analysis. J Chem Neuroanat 15: 173-185.

Price JL, Amaral DG (1981). An autoradiographic study of the projections of the central nucleus of the monkey amygdala. J Neurosci 1: 1242-1259.

Roth RH, Murrin LC, Walters JR (1976). Central dopaminergic neurons: effects of alterations in impulse flow on the accumulation of dihydroxyphenylacetic acid. Eur J Pharmacol 36: $163-171$.

Roth RH, Tam SY, Ida Y, Yang JX, Deutch AY (1988). Stress and the mesocorticolimbic dopamine systems. Ann NY Acad Sci 537: 138-147.

Roth RH, Walters JR, Aghajanian GK (1973). Effect of impulse flow on the release and synthesis of dopamine in the rat striatum. In: Usdin E, Snyder S (eds). Frontiers in Catecholamine Research. Pergamon Press: New York. pp 567-574.

Salamone JD (1994). The involvement of nucleus accumbens dopamine in appetitive and aversive motivation. Behav Brain Res 61: 117-133.
Schultz W (1998). Predictive reward signal of dopamine neurons. J Neurophysiol 80: 1-27.

Smith-Roe SL, Kelley AE (2000). Coincident activation of NMDA and dopamine D1 receptors within the nucleus accumbens core is required for appetitive instrumental learning. J Neurosci 20: $7737-7742$.

Sullivan RM, Gratton A (1998). Relationships between stressinduced increases in medial prefrontal cortical dopamine and plasma corticosterone levels in rats: role of cerebral laterality. Neuroscience 83: 81-91.

Thierry AM, Tassin JP, Blanc G, Glowinski J (1976). Selective activation of mesocortical DA system by stress. Nature 263: 242-244.

Trampus M, Ferri N, Adami M, Ongini E (1993). The dopamine D1 receptor agonists, A68930 and SKF 38393, induce arousal and suppress REM sleep in the rat. Eur J Pharmacol 235: 83-87.

Trampus M, Ferri N, Monopoli A, Ongini E (1991). The dopamine D1 receptor is involved in the regulation of REM sleep in the rat. Eur J Pharmacol 194: 189-194.

Van Bockstaele EJ, Colago EE, Valentino RJ (1998). Amygdaloid corticotropin-releasing factor targets locus coeruleus dendrites: substrate for the co-ordination of emotional and cognitive limbs of the stress response. J Neuroendocrinol 10: 743-757.

Vanderwolf CH, Robinson TE (1981). Reticulo-cortical activity and behavior: a critique of the arousal theory and a new synthesis. Behav Brain Sci 4: 459-514.

Walker DL, Davis M (1997). Double dissociation between the involvement of the bed nucleus of the stria terminalis and the central nucleus of the amygdala in startle increases produced by conditioned versus unconditioned fear. I Neurosci 17: 9375-9383.

Walker DL, Davis M (2002). The role of amygdala glutamate receptors in fear learning, fear- potentiated startle, and extinction. Pharmacol Biochem Behav 71: 379-392.

Wallace DM, Magnuson DJ, Gray TS (1992). Organization of amygdaloid projections to brainstem dopaminergic, noradrenergic, and adrenergic cell groups in the rat. Brain Res Bull 28: 447-454.

Whalen PJ (1998). Fear, vigilance, and ambiguity: initial neuroimaging studies of the human amygdala. Curr Direct Psychol Sci 7: $177-188$

Williams GV, Goldman-Rakic PS (1995). Modulation of memory fields by dopamine D1 receptors in prefrontal cortex. Nature 376: $572-575$.

Wise RA, Rompre PP (1989). Brain dopamine and reward. Annu Rev Psychol 40: 191-225.

Wood PL, Altar CA (1988). Dopamine release in vivo from nigrostriatal, mesolimbic, and mesocortical neurons: utility of 3-methoxytyramine measurements. Pharmacol Rev 40: 163-187.

Zahm DS, Jensen SL, Williams ES, Martin III JR (1999). Direct comparison of projections from the central amygdaloid region and nucleus accumbens shell. Eur J Neurosci 11: $1119-1126$. 